\title{
Examining exercise motives between gender, age and activity: A first-order scale analysis and measurement invariance
}

\author{
Filipe Rodrigues $^{1,2,3}$ (D) - J. Moutão $0^{2,3} \cdot$ D. Teixeira ${ }^{4} \cdot$ L. Cid $^{2,3} \cdot$ D. Monteiro ${ }^{2,3}$
}

(C) Springer Science+Business Media, LLC, part of Springer Nature 2019

\begin{abstract}
Conceptualizing an exercise program according to exercisers motives seems to be crucial. Thus, adequate and validated scale assessing motives for physical activity is necessary. This study aimed to translate and validate the Exercise Motives Inventory -2 (EMI-2), a scale assessing fourteen motives for regular physical activity in Portuguese exercisers. In addition, comparison of motives between groups were made according to gender, age, and fitness activity. For scale validation, data from two independent samples were collected: calibration $(n=820$; female $=499)$ and validation $(n=733$; female $=451)$ participants. For scale reliability and mean difference analysis, data from a new sample was collected $(n=515$; female $=342)$. Results showed that data did not fit the original 51-item model. After reviewing item loadings, two items were eliminated, since they presented factor loadings below acceptable. Hence, the revised model encompassing 49-item had an adequate fit. Convergent and discriminant validity was achieved in the revised model, displaying acceptable construct validity. In addition, invariance criteria were respected between female and male Portuguese exercisers. Regarding mean comparison analysis, differences were found between gender, and across age and fitness activities. Nevertheless, in overall the majority of exercisers indicated "general health" and "physiological" motives as the most valued. The EMI-2 is a reliable scale assessing motives in Portuguese exercisers. This study suggests that exercise programs should be conceptualized considering motives, but also gender, age, and fitness activity.
\end{abstract}

Keywords Exercise $\cdot$ Motives $\cdot$ Confirmatory analysis $\cdot$ Measurement invariance $\cdot$ Mean differences

\section{Physical activity and motives}

"What drives you to exercise?" is possibly one of the most frequently asked questions by exercise professionals and peers when someone engages in physical activity for the first time. Research on understanding the motives for individuals to choose to exercise could be of great practical value (Markland and Hardy 1993) and therefore conceptualizing an exercise program according to exercisers motives seems to be essential. Concerning exercising, goals of pleasure,

Filipe Rodrigues

ptfiliperodrigues@gmail.com

1 Sports Science Department, University of Beira Interior, Covilhã, Portugal

2 Research Center in Sport, Health and Human Development (CIDESD), Vila Real, Portugal

3 Sport Science School of Rio Maior (ESDRM-IPSantarém), Av. Dr. Mário Soares n¹10, 2040-413 Rio Maior, Portugal

4 University of Lusófona, Lisbon, Portugal competence and self-regulation are conceptualized as internal motives and will have positive effects such as exercise persistence (Markland and Hardy 1993; Markland and Ingledew 1997). However, goals which pressure people to participate in physical activity can create anxiety and tension, hence, they are defined as external motives and may have adverse effects such as exercise withdrawal (Ingledew and Markland 2008).

This notion of intrinsic and extrinsic motives has been keenly studied by Ryan and Deci (2017), suggesting that to behave in an informational manner leads to positive results, and that to regulate oneself in a controlling fashion lead to negative outcomes. In a theoretical manner, exercising by internal motives (e.g., because of pleasure, enjoyment, revitalization) will influence intrinsic motivation and subsequent positive outcomes (Sebire et al. 2008). On the other hand, people engaging in exercise because of external drives (e.g., social recognition, appraisal, appearance) are more likely to experience controlled motivation, resulting in higher rates of dropout (Ryan et al. 1997). Nevertheless, exercise may be adopted at first for external reasons such as body image and social recognition, but, as physical fitness and well-being increases, self-determined reasons may become more noticeable 
(Ingledew and Markland 2008). Hence, motives may change over time as a response to being actively involved in regular exercise participation.

Individuals have different reasons for engaging in physical exercise. Some for increasing physical fitness (e.g., speed, strength, endurance), others for health-related outcomes (e.g., decrease diabetes side effects), and/or even for social acceptance (e.g., belong to a club). In this regard, individual's characteristics could impact motives for exercise participation (Cid et al. 2007; Klain et al. 2015). For example Ingledew et al. (1998) suggest that women endorse in physical activity mainly for external reasons (e.g., body image, acceptance by others) and men mostly for internal reasons (e.g., enjoyment, health and self-esteem). Dacey et al. (2008) have shown that older people are more likely to participate in physical activity for health, physical fitness, and enjoyment. Therefore, understanding what drives someone to exercise regularly seems paramount to actively keep follow-up their adherence.

\section{Exercise Motives Measurement}

When it comes to measuring motives, several instruments have been used in the exercise context: Duda and Tappe (1988) created the Personal Incentives for Exercise Questionnaire (PIEQ); Frederick and Ryan (1993) designed the Motivation for Physical Activity (MPAM), and Markland and Hardy (1993) developed the Exercise Motives Inventory (EMI). Looking individually at each instrument, the PIEQ is a 49-item questionnaire comprising seven subscales (i.e., mastery, competition, social affiliation, recognition, health benefits, coping with stress, and physical fitness). However, it has been suggested to suffer from a number of problems such as construct validity, influencing its applicability in the actual context (Markland and Hardy 1993; Molanorouzi et al. 2014). The original MPAM encompassing three motives (i.e., interest/enjoyment, competence, and body-related motivation) was later reviewed and expanded by Ryan et al. (1997) encompassing two more motives namely fitness and social aspiration. However, this instrument continues to be limited on measuring exercise related-goals compared to other instruments such as the EMI-2 which considers 14 motives (Markland and Ingledew 2007). In this regard, the EMI and latter EMI-2 seems to hold higher validity compared to previous reported scales and has been applied successfully in several research led in the exercise domain, specifically in older adults (Dacey et al. 2008), in gym and health center clients (Klain et al. 2015), and even in young adults (Ingledew and Markland 2008).

Markland and Hardy (1993) created the EMI based on three sources: 1) open-ended responses provided by a sample of regular exercisers, stating three main motives on why they choose to exercise; 2) items rooted within the PIEQ, and; 3 ) motives reported in the literature. The EMI-2 (Markland and Ingledew 1997) was settled to extend the previous instrument, by reviewing the original one. This upgraded version contains 51 items defining 14 constructs, assessing a broader range of motives exercisers have. Thus, the EMI-2 measures the following motives: stress management, revitalization, enjoyment, challenge, health pressure, ill-health avoidance, positive health, agility, strength and endurance, weight management, appearance, social recognition, affiliation, and competition. In addition, Markland and Ingledew (1997) proposed that these fourteen motives could be grouped into five second-order groups: psychological (stress management, revitalization, enjoyment, and challenge); interpersonal (affiliation, social recognition, and competition); health (health pressure, positive health, and ill-health avoidance); physical condition (agility, strength and endurance), and body (weight management, appearance).

Since its validation, the EMI-2 has been translated in several different languages, namely: English, Spanish, Portuguese, German, Arab, and Slovenian, suggesting that this scale holds a broad appeal as a method of assessing exercise motives. Ingledew and Markland (2008) have shown this scale to be reliable on measuring exercise motives, hence, it appears useful to measure a broad display of intrinsic and extrinsic reasons.

Although several authors (Ortís et al. 2007; Roberts et al. 2014) have determined high levels of applicability of the EMI2 , past research displays some issues that needs to be addressed. First, to the best of our knowledge, no study has ever tested the 51-item scale encompassing all aspirations in one measurement model. Previous studies have conducted exploratory analysis (Markland and Hardy 1993) or confirmatory analysis in each factor individually (Klain et al. 2015). Other studies such as Baptista et al. (2014) adapted the instrument into a shorter version (14-item) considering only one item per factor, encompassing them into three motives (psychological and physical well-being, health, and social). However, this does not represent the EMI-2 true nature falling short on assessing adjusted psychometric properties. In addition, the model displayed adequate fit only after correlating standard errors between items from different factors, which is not recommended by statistical guidelines for measurement model analysis (Hair et al. 2014).

Looking at past literature, there seems to be a gap in the literature on testing a first-order model analysis considering all fourteen exercise motives. In other words, no measurement model considering all exercise aspirations has been tested and this is a gap that needs to be addressed to accept or reject adjusted psychometric proprieties of the EMI-2. Even the first authors of the EMI-2 came short since they had to eliminate four motives (i.e., challenge, ill-health avoidance, enjoyment, and revitalization) from the original scale to achieve acceptable results. In fact, Markland and Ingledew (1997) 
recommended further analysis of this instrument to achieve model fit as close as possible to the original 14-motives. In addition, no study conducted till date with Portuguese exercisers measured invariance between different groups (e.g., gender). This presents a relevant gap that needs to been filled since invariance analyses are need to understand if the EMI-2 is equivalent among groups with different characteristics as suggested by Chen (2008).

\section{Present Research}

Considering limitations from previous studies and agenda for future research, current study (Study 1) aimed to validate the EMI-2 in a Portuguese sample considering all fourteen aspirations in one measurement model. Construct validity, internal consistency, convergent and discriminant validity, as well as measurement invariance analysis were performed on the EMI2 to examine the psychometric proprieties and scale reliability. In addition, means between groups (i.e., gender, age, fitness activities) were compared to assess differences (Study 2). Understanding the dimensionality of the EMI-2 could give new insights on how fitness professionals should assign training sessions to promote long-term exercise participation.

It is hypothesized that the EMI-2 would hold acceptable fit in Portuguese exercisers as it has presented in previous studies (Markland and Ingledew 2008; Dacey et al. 2008). In addition, we suspect differences in exercise motives among gender (Markland and Ingledew 1997), age (Dacey et al. 2008), and fitness activities.

\section{Study 1}

\section{Methods}

\section{Participants and Procedures}

In order to measure reliability, we collected data from two independent samples (i.e., calibration and validation). The calibration sample was composed by 733 Portuguese exercisers (female $=451)$ aged between 18 and 75 years $(M=$ 34.73; $\mathrm{SD}=11.66)$. Exercise experience ranged from 4 months to 166 months $(\mathrm{M}=55.74 ; \mathrm{SD}=6.97)$ and endorsed activities generally were fitness group classes $(n=112)$, swimming pool activities such as water gymnastic $(n=100)$, and weightlifting/cardio training $(n=255)$.

In validation sample, 820 Portuguese exercisers (female $=$ 499) aged between 18 and 76 years $(M=34.69$; $\mathrm{SD}=11.70)$ were enrolled for analysis. Exercise experience ranged from 3 months to 180 months $(M=60.49$; $\mathrm{SD}=8.54)$. Performed activities were mostly fitness group classes $(n=112)$, swimming pool activities such as water gymnastic $(n=114)$, and weightlifting/cardio training $(\mathrm{n}=102)$.

Research was approved by the Ethical Committee previous to data collection. Afterwards, sixteen managers from different Portuguese gym and health centers were contacted, studies objectives were explained, and agreement was obtained. By convenience at reception desk, individuals were approached before training sessions and asked to participate voluntary in this study. Thus, data collected from these first exercisers were considered for calibration sample. Six months later, new data was collected, representing validation sample. Information sheets were distributed for all potential participants and informed consent was signed before filling the questionnaire. Individuals took approximately $10-15 \mathrm{~min}$ to complete the demographic form and the EMI-2.

\section{Measures}

To assess exercise motives, the Exercise Motives Inventory - 2 Portuguese version (Alves and Lourenço 2003) was used. This scale encompasses 51 items, asking participants to answer on a 6-point scale with verbal anchors located at 0 ("not at all true for me") and 5 ("very true for me"). Looking at factors (i.e., fourteen), five where composed by three items (revitalization, ill-health avoidance, health pressure, positive health, and agility) and the others by four items (stress management, enjoyment, challenge, social recognition, affiliation, competition, weight management, appearance, and strength and endurance). Several studies (Ingledew and Markland 2008; Markland and Ingledew 1997; Ortís et al. 2007) support the use of this scale for measuring exercise motives.

\section{Statistical Analysis}

Descriptive statistics were calculated and data was screened for missing values previous to confirmatory analysis. Participants with more than $5 \%$ of missing values, univariate $(\mathrm{z}>3)$ and multivariate $\left(\mathrm{D}^{2}=\mathrm{p} 1<.001, \mathrm{p} 2<.001\right)$ outliers were excluded as recommended by Byrne (2016). Data from questionnaires with less than $5 \%$ of absent scores was imputed using the Full Information Maximum Likelihood estimation (FIML) (Cham et al. 2017).

A Confirmatory Factor Analysis (CFA) to measure model fit was performed using IBM SPSS AMOS 23.0. Maximum Likelihood method was conducted since this estimation is a viable option for estimating factor models using continuous variables (DiStefano and Hess 2016; Schmitt 2011). Test for common method bias was tested prior to a fourteen measurement model, following Podsakoff et al. (2003) guidelines. Measurement model adequacy was verified by the traditional absolute and incremental indexes, namely: Comparative Fit Index (CFI), Non-Normed Fit Index (NNFI), Standard Root Mean Residual (SRMR), Root Mean Square Error of 
Approximation (RMSEA), and its respective 90\% Confidence Interval $(90 \% \mathrm{CI})$. Cutoffs recommended by several authors (Byrne 2016; Hair et al. 2014; Marsh et al. 2004) were used, namely: CFI and TLI $\geq .90$, and SRMR and RMSEA $\leq .80$. We tested second-order CFA model using the same cutoffs fit indexes. However, according to some authors (Kenny and McCoach 2003), in very complex models CFI tends to decline even if the model is properly specified. Therefore, these authors suggest accepting the model if the CFI is slightly lower as recommended, thus RMSEA needs to be acceptable. Models should be rejected if both CFI and RMSEA are below cutoffs (Kenny and McCoach 2003). Composite Reliability (CR) was calculated using Raykov (1997) formula to test internal consistency considering scores above .70 as acceptable. Convergent and discriminant validity were assessed to test if the items converged to the same factor and if factors are sufficiently distinct from each other, respectively. Average Variance Extracted (AVE) was calculated and values above .50 were defined as acceptable for convergent validity. Squared correlations across constructs should be below AVE scores to achieve discriminant validity as recommended by Hair et al. (2014).

Measurement invariance was conducted in order to test if the model would exhibit the same fit between calibration and validation sample, as well as between gender. This type of analysis enables to measure the equivalence of the measurement model between groups with different characteristics (Cheung and Rensvold 2002; Meredith 1993; Sass 2011). A multi-group analysis was performed according to several recommendations (Chen 2007; Cheung and Rensvold 2002), namely: i) the measurement model should have good fit in each group, and; ii) differences $(\Delta) \mathrm{CFI} \leq .01$ for configural invariance, $\triangle \mathrm{SRMR}<.03$ and $\triangle \mathrm{RMSEA}<.015$ for metric invariance, and $\triangle \mathrm{SRMR}<.01$ and $\triangle \mathrm{RMSEA}<.015$ for scalar invariance. Residual invariance is considered optional since it difficult to achieve in the field of social sciences, as suggested by Byrne (2016).

\section{Results}

\section{Preliminary Analysis}

Concerning calibration sample, 29 participants were eliminated since they presented $>5 \%$ of missing values in all items. In addition, 11 univariate and 14 multivariate outliers were eliminated for subsequent analysis. In validation sample, 24 individuals with missing values $>5 \%, 12$ univariate, and 5 multivariate outliers were excluded from further analysis. Descriptive statistics revealed univariate distribution, since skewness and kurtosis were contained within cutoffs in both samples. Descriptive statistics for calibration and validation sample are displayed in Tables 1 and 2, respectively. Positive health motive presented the highest mean, whereas social recognition showed the lowest mean in both groups. Exercise motives displayed CR coefficient above cutoffs, suggesting acceptable internal consistency.

\section{Confirmatory Factorial Analysis}

Test for common method bias showed that total explained variance was below 50\%. Thus, a measurement model considering fourteen factors was analyzed. Multivariate normality was violated since Mardia's coefficient exceeded cutoffs in both groups. In this regard, a Bollen-Stine bootstrap of 2000 samples was inserted as recommended by Nevitt and Hancock (2001). The measurement model using the original 51-item scale was close to fit the data as seen in Table 3. Hence, modification indexes and possible cross-loadings were examined in detail. Results show that item 4 (i.e., appearance) and item 6 (i.e., stress management) presented factor loadings below cutoffs and were therefore eliminated.

The revised measurement model considering 49 items had an acceptable fit as displayed in Table 3 in both samples. Item loadings ranged from .55 (weight management) to .91 (competition) in calibration sample, and from .58 (positive health) to .91 (competition) in validation sample. Hence, factor loadings explain at least $25 \%$ of latent factors variance (see Table 4).

Then, a second-order model was tested according to previous reported literature. Looking at traditional and incremental indexes, the second-order model did not fit the data. Once more, modification indexes and cross-loadings were analyzed to explain current results. All factor weights were above .50 and no significant cross-loadings were found. However, since model had a poor fit (i.e., CFI and RMSEA below cutoffs), the second-order model was rejected.

Convergent validity was achieved since AVE scores were above acceptable. Looking at discriminant validity, 90 of 91 interactions achieved expected results. Stress management and revitalization did not present discriminant validity. Nevertheless, the lack of discriminant validity in these factors was residual as see in Tables 1 and 2.

\section{Multi-Group Analysis}

Results revealed that the measurement model is invariant between samples and gender based on recommended criteria (see Table 5). Specifically, the model fit in each sample and differences between indexes were below suggested cut-off values.

\section{Discussion}

The aim of the present study was to test and validate the original EMI-2, a 51-item instrument measuring 14 motives 
Table 1 Descriptive statistics, composite reliability, average mean extracted, and squared correlation matrix in calibration sample

\begin{tabular}{|c|c|c|c|c|c|c|c|c|c|c|c|c|c|c|c|c|c|c|}
\hline & \multirow[t]{2}{*}{ M } & \multirow[t]{2}{*}{ SD } & \multirow[t]{2}{*}{$\mathrm{CR}$} & \multirow[t]{2}{*}{ AVE } & \multicolumn{14}{|l|}{$r^{2}$} \\
\hline & & & & & 1 & 2 & 3 & 4 & 5 & 6 & 7 & 8 & 9 & 10 & 11 & 12 & 13 & 14 \\
\hline 1. Stress Management & 3.74 & 1.07 & .87 & .83 & 1 & & & & & & & & & & & & & \\
\hline 2. Revitalization & 4.03 & .78 & .75 & .70 & .72 & 1 & & & & & & & & & & & & \\
\hline 3. Enjoyment & 3.73 & .96 & .87 & .79 & .46 & .70 & 1 & & & & & & & & & & & \\
\hline 4. Challenge & 2.47 & 1.18 & .83 & .74 & .18 & .27 & .46 & 1 & & & & & & & & & & \\
\hline 5. Health Pressure & 1.78 & 1.40 & .83 & .78 & .57 & .01 & .46 & .15 & 1 & & & & & & & & & \\
\hline 6. Positive Health & 4.24 & 1.01 & .73 & .72 & .05 & .31 & .01 & .16 & .04 & 1 & & & & & & & & \\
\hline 7. Ill-Health Avoidance & 3.61 & .74 & .82 & .78 & .29 & .43 & .12 & .12 & .61 & .23 & 1 & & & & & & & \\
\hline 8. Agility & 3.74 & .93 & .89 & .85 & .34 & .03 & .41 & .25 & .48 & .03 & .20 & 1 & & & & & & \\
\hline 9. Strength and Endurance & 3.49 & .91 & .81 & .72 & .33 & .15 & .53 & .44 & .58 & .05 & .27 & .13 & 1 & & & & & \\
\hline 10. Affiliation & 2.56 & 1.22 & .88 & .80 & .16 & .13 & .53 & .53 & .09 & .13 & .06 & .18 & .18 & 1 & & & & \\
\hline 11. Social Recognition & 1.11 & 1.16 & .91 & .85 & .01 & .02 & .09 & .52 & .01 & .05 & .04 & .57 & .15 & .35 & 1 & & & \\
\hline 12. Competition & 1.72 & 1.38 & .92 & .86 & .02 & .04 & .18 & .66 & .03 & .19 & .02 & .09 & .19 & .41 & .66 & 1 & & \\
\hline 13. Weight Management & 3.24 & 1.14 & .87 & .78 & .13 & .07 & .07 & .10 & .19 & .08 & .26 & .13 & .18 & .07 & .03 & .07 & 1 & \\
\hline 14. Appearance & 2.99 & 1.26 & .91 & .88 & .15 & .12 & .15 & .21 & .22 & .04 & .17 & .16 & .28 & .11 & .06 & .12 & .46 & 1 \\
\hline
\end{tabular}

$M$ Mean, $S D$ Standard Deviation, $C R$ Composite Reliability, $A V E$ Average Variance Extracted, $r^{2}$ squared correlation, $C F A$ model with 49 -items

for exercise participation, in a sample of Portuguese individuals. A CFA was conducted, considering the traditional and incremental indexes, convergent and discriminant validity, as well as internal consistency. We also tested a second-order model converging fourteen motives into five second-order factors as proposed by several authors (Markland and Hardy 1993; Markland and Ingledew 1997). To increase measurement reliability, measurement invariance analysis was conducted between two independent samples and gender.

\section{Confirmatory Factor Analysis}

The first step was to develop the first-order factor model of the EMI-2 and examine its validity. The first-order CFA of the 51item instrument on both samples extracted fourteen correlated but distinct factor, measuring different motives for exercise participation. However, this model did not fit the data and thus modification indexes had to be analyzed to assess possible issues. No cross-loadings where found, but two items (item

Table 2 Descriptive statistics, composite reliability, average mean extracted, and squared correlation matrix in validation sample

\begin{tabular}{|c|c|c|c|c|c|c|c|c|c|c|c|c|c|c|c|c|c|c|}
\hline & \multirow[t]{2}{*}{$\mathrm{M}$} & \multirow[t]{2}{*}{ SD } & \multirow[t]{2}{*}{$\mathrm{CR}$} & \multirow[t]{2}{*}{ AVE } & \multicolumn{14}{|l|}{$r^{2}$} \\
\hline & & & & & 1 & 2 & 3 & 4 & 5 & 6 & 7 & 8 & 9 & 10 & 11 & 12 & 13 & 14 \\
\hline 1. Stress Management & 3.73 & 1.08 & .87 & .83 & 1 & & & & & & & & & & & & & \\
\hline 2. Revitalization & 4.02 & .79 & .74 & .73 & .76 & 1 & & & & & & & & & & & & \\
\hline 3. Enjoyment & 3.71 & .98 & .87 & .80 & .46 & .73 & 1 & & & & & & & & & & & \\
\hline 4. Challenge & 2.44 & 1.18 & .82 & .73 & .18 & .28 & .47 & 1 & & & & & & & & & & \\
\hline 5. Health Pressure & 1.75 & 1.39 & .83 & .78 & .57 & .77 & .46 & .17 & 1 & & & & & & & & & \\
\hline 6. Positive Health & 4.23 & .75 & .72 & .68 & .05 & .04 & .01 & .16 & .61 & 1 & & & & & & & & \\
\hline 7. Ill-Health Avoidance & 3.59 & 1.01 & .81 & .77 & .29 & .42 & .13 & .12 & .04 & .25 & 1 & & & & & & & \\
\hline 8. Agility & 3.71 & .96 & .89 & .85 & .35 & .62 & .43 & .25 & .50 & .04 & .22 & 1 & & & & & & \\
\hline 9. Strength and Endurance & 3.47 & .95 & .81 & .72 & .33 & .56 & .56 & .44 & .60 & .06 & .28 & .59 & 1 & & & & & \\
\hline 10. Affiliation & 2.55 & 1.22 & .87 & .80 & .17 & .15 & .35 & .52 & .14 & .14 & .07 & .10 & .20 & 1 & & & & \\
\hline 11. Social Recognition & 1.08 & 1.16 & .91 & .84 & .01 & .02 & .08 & .53 & .01 & .32 & .04 & .03 & .14 & .34 & 1 & & & \\
\hline 12. Competition & 1.69 & 1.38 & .91 & .85 & .02 & .04 & .18 & .68 & .03 & .20 & .02 & .05 & .18 & .40 & .18 & 1 & & \\
\hline 13. Weight Management & 3.21 & 1.16 & .87 & .79 & .14 & .16 & .08 & .11 & .19 & .09 & .27 & .13 & .18 & .07 & .09 & .03 & 1 & \\
\hline 14. Appearance & 2.96 & 1.27 & .92 & .85 & .17 & .29 & .24 & .28 & .28 & .04 & .17 & .20 & .16 & .14 & .03 & .08 & .47 & 1 \\
\hline
\end{tabular}

$M$ Mean, $S D$ Standard Deviation, $C R$ Composite Reliability, AVE Average Variance Extracted, $r^{2}$ squared correlation; CFA model with 49-items 
Table 3 Fit adjustment of confirmatory factor analysis

\begin{tabular}{|c|c|c|c|c|c|c|c|c|c|}
\hline & $\chi^{2}$ & df & $\chi^{2 / \mathrm{df}}$ & $B-S p$ & CFI & NNFI & SRMR & RMSEA & $90 \% \mathrm{CI}$ \\
\hline \multicolumn{10}{|l|}{ Study 1} \\
\hline Calibration Sample 1st order * & 3496.244 & 1133 & 3.09 & $<.001$ & .90 & .88 & .07 & .06 & $.056 / .060$ \\
\hline Calibration Sample 1st order & 3040.077 & 1036 & 2.94 & $<.001$ & .91 & .90 & .056 & .06 & $.054 / .058$ \\
\hline Calibration Sample 2nd order & 3957.722 & 1103 & 3.60 & $<.001$ & .87 & .86 & .09 & .07 & $.063 / .067$ \\
\hline Validation Sample 1st order & 3131.843 & 1036 & 3.03 & $<.001$ & .91 & .90 & .06 & .06 & $.054 / .059$ \\
\hline Validation Sample 2nd order & 4070.664 & 1103 & 3.70 & $<.001$ & .867 & .86 & .09 & .07 & $.063 / .068$ \\
\hline Female Sample & 4649.642 & 1035 & 4.49 & $<.001$ & .90 & .90 & .06 & .07 & $.064 / .068$ \\
\hline Male Sample & 3549.018 & 1036 & 3.43 & $<.001$ & .91 & .90 & .06 & .06 & $.058 / .062$ \\
\hline \multicolumn{10}{|l|}{ Study 2} \\
\hline Third sample & 2994.412 & 1036 & 2.89 & $<.001$ & .91 & .91 & .06 & .06 & $.059 / .063$ \\
\hline
\end{tabular}

$\chi 2$ chi-square, $d f$ degrees of freedom, $\chi 2 / d f$ normative chi-square, B-S $p$ Bollen-Stine bootstrap (2000 samples), CFI Comparative Fit Index, NNFI NonNormed Fit Index, SRMR Standardized Root Mean Square Residual, RMSEA Root Mean Squared Error of Approximation, $90 \%$ CI Confidence Interval of RSMEA; * =51-item model, all other models were tested with 49-items (final model)

4 - appearance) and (item 6 - stress management) had factor loadings below cutoffs. Thus, according to several authors (Byrne 2016; Hair et al. 2014) these items were removed. The revised model (49 items) had acceptable fit in both samples and internal consistency was above acceptable. Also, convergent validity was achieved and discriminant analysis showed that 90 of 91 possible interactions were considered acceptable. In the present research, only stress management with revitalization did not exhibited discriminant validity. This could be explained by their representation of psychological motives for exercise. As stated by Markland and Ingledew (1997), both factors could converge into a second-order factor named "psychological", since they explain perceptions of how they experience exercise in a personal manner. Nevertheless, squared correlation among these factors was residual compared to AVE scores.

In overall, results from this study measuring the psychometric proprieties of the EMI-2 are novel since it was the first time a research used all fourteen exercise motives in one measurement model. Current findings advance previous studies using this scale (Dacey et al. 2008; Ingledew and Markland 2008; Markland and Ingledew 1997) showing that this instrument has acceptable psychometric properties.

Looking at the second-order model specification encompassing all motives into five hypothesized groups (i.e., psychological, health, body image, physical fitness, and interpersonal), analysis was conducted according to theoretical assumptions proposed by Markland and Ingledew (1997). The second-order model in the present study did not achieve fit. Although Kenny and McCoach (2003) suggest that CFI could suffer from complex models such as second-order confirmatory analysis, and that scores proximal to cutoffs should be considered as acceptable if RMSEA is $<.06$, the present results are not close to being considered suitable. It is worth to mention that there is virtually no study that has ever tried a second-order analysis on the EMI-2. In fact, past studies have only examined the psychometric properties of each factor individually (Klain et al. 2015; Markland and Hardy 1993; Markland and Ingledew 1997). Nevertheless, present findings suggest the EMI-2 to be a reliable instrument on measuring exercise motives in Portuguese exercisers.

\section{Multi-Group Analysis}

With respect to multi-group analysis between samples and gender, results support the equivalence of EMI-2 between groups since all invariance assumptions were met as suggested by several authors (Byrne 2016; Chen 2007; Cheung and Rensvold 2002). Present findings exhibit that regardless of sample groups, all factors weights were invariant (configural invariance). In addition, items have the same importance for all factors (metric invariance) and are equally between samples and gender (scalar invariance). These results suggest that the measurement model is invariant between samples and gender (Hair et al. 2014).

However, differences between male and female exercisers can only be assessed comparing means between them. Vlachopoulos et al. (2013) suggest that there are differences when it comes to perceiving the "why's" behind exercising. Latent mean differences analysis was not possible to perform since sample size was below minimum recommended (Hair et al. 2014). Specifically, following guidelines of 5 participants per estimated parameter, sample size in this study $(n=$ $1553)$ was below estimated parameters $(n=1036)$.

Several studies have shown mean differences between sample characteristics, stating the importance measuring exercise motives have when prescribing training sessions (Smith et al. 1998). Hence, new data was collected in order to test scale reliability and to compare motives across groups with different characteristics (i.e., gender, age, and fitness activity). 
Table 4 Factor loadings of the 49-item model

\begin{tabular}{|c|c|c|c|c|c|}
\hline \multirow[t]{2}{*}{ Item } & \multirow[t]{2}{*}{ Factor } & \multicolumn{2}{|c|}{ Calibration Sample } & \multicolumn{2}{|c|}{ Validation Sample } \\
\hline & & $\lambda$ & S.E. & $\lambda$ & S.E. \\
\hline 1 & WM & .59 & .34 & .60 & .36 \\
\hline 2 & ILL & .69 & .48 & .69 & .48 \\
\hline 3 & REV & .60 & .35 & .60 & .36 \\
\hline 4 & APP & - & - & - & - \\
\hline 5 & SOC & 82. & .67 & .81 & .66 \\
\hline 6 & $\mathrm{SM}$ & - & - & - & - \\
\hline 7 & $\mathrm{PH}$ & .69 & .48 & .70 & .50 \\
\hline 8 & SR & .68 & .46 & .69 & .47 \\
\hline 9 & JOY & .77 & .60 & .78 & .62 \\
\hline 10 & AFFI & .82 & .67 & .82 & .67 \\
\hline 11 & HPR & .58 & .33 & .60 & .36 \\
\hline 12 & COMP & .82 & .67 & .82 & .67 \\
\hline 13 & $\mathrm{AG}$ & .77 & .59 & .77 & .60 \\
\hline 14 & CHAL & .71 & .51 & .70 & .50 \\
\hline 15 & WM & .84 & .70 & .84 & .70 \\
\hline 16 & ILL & .85 & .59 & .86 & .74 \\
\hline 17 & REV & .70 & .49 & .70 & .49 \\
\hline 18 & APP & .87 & .76 & .87 & .76 \\
\hline 19 & SOC & .84 & .71 & .84 & .70 \\
\hline 20 & $\mathrm{SM}$ & .73 & .53 & .73 & .52 \\
\hline 21 & $\mathrm{PH}$ & .82 & .68 & .82 & .68 \\
\hline 22 & SR & .78 & .60 & .77 & .59 \\
\hline 23 & JOY & .81 & .66 & .82 & .67 \\
\hline 24 & AFFI & .76 & .57 & .76 & .57 \\
\hline 25 & HPR & .67 & .44 & .67 & .45 \\
\hline 26 & COMP & .91 & .83 & .91 & .83 \\
\hline 27 & $\mathrm{AG}$ & 89. & .78 & .88 & .78 \\
\hline 28 & CHAL & .80 & .64 & .81 & .28 \\
\hline 29 & WM & .88 & .84 & .87 & .71 \\
\hline 30 & ILL & .77 & .48 & .77 & .60 \\
\hline 31 & REV & .80 & .64 & .80 & .64 \\
\hline 32 & APP & .90 & .77 & .90 & .81 \\
\hline 33 & SOC & .88 & .75 & .88 & .78 \\
\hline 34 & $\mathrm{SM}$ & .87 & .76 & .87 & .82 \\
\hline 35 & $\mathrm{PH}$ & .83 & .68 & .83 & .69 \\
\hline 36 & SR & .77 & .60 & .77 & .59 \\
\hline 37 & JOY & .85 & .72 & .84 & .70 \\
\hline 38 & AFFI & .78 & .61 & .78 & .61 \\
\hline 39 & HPR & .80 & .59 & .80 & .60 \\
\hline 40 & COMP & .86 & .73 & .86 & .75 \\
\hline 41 & $\mathrm{AG}$ & .90 & .81 & .89 & .78 \\
\hline 42 & CHAL & .68 & .74 & .69 & .48 \\
\hline 43 & WM & .84 & .71 & .84 & .71 \\
\hline 44 & APP & .88 & .77 & .88 & .78 \\
\hline 45 & SOC & .86 & .75 & .86 & .74 \\
\hline 46 & $\mathrm{SM}$ & .90 & .81 & .90 & .82 \\
\hline 47 & SR & .65 & .42 & .64 & .41 \\
\hline
\end{tabular}

Table 4 (continued)

\begin{tabular}{|c|c|c|c|c|c|}
\hline \multirow[t]{2}{*}{ Item } & \multirow[t]{2}{*}{ Factor } & \multicolumn{2}{|c|}{ Calibration Sample } & \multicolumn{2}{|c|}{ Validation Sample } \\
\hline & & $\lambda$ & S.E. & $\lambda$ & S.E. \\
\hline 48 & JOY & .75 & .57 & .74 & .54 \\
\hline 49 & AFFI & .84 & .70 & .85 & .72 \\
\hline 50 & COMP & .86 & .70 & .84 & .70 \\
\hline 51 & CHAL & .74 & .55 & .75 & .54 \\
\hline
\end{tabular}

JOY Enjoyment, SOC Social Recognition, AFFI Affiliation, COMP Competition, $W M$ Weight Management, $S R$ Strength and Resistance, CHAL Challenge, SM Stress Management, APP Appearance, ILL IllHealth Avoidance, $P H$ Positive Health, $H P R$ Health Pressure, $A G$ Agility, REVI Revitalization

\section{Study 2 \\ Methods}

\section{Participants and Procedures}

To support scale reliability, data from a third independent sample was collected. For analysis, 515 Portuguese exercisers aged between 18 and 74 years $(M=34.73 ; \mathrm{SD}=11.73)$ were considered. Exercise experience ranged from 4 months to 177 months $(M=58.47 ; S D=7.98)$. Performed activities were fitness group classes (e.g., aerobics, total workout, step, Pilates), swimming pool activities (e.g., water gymnastics, hidrocycling), and weightlifting/cardio training.

We followed the same procedures as in Study 1 regarding data collection. However, in this study for inclusion potential participants needed to be actively taking part in one of the most reported gym activities in Study 1 (i.e., fitness group classes, swimming pool activities, and weightlifting/cardio training), aged equal or above 18 years, and participate voluntarily in this study.

\section{Measures}

The previously tested and validated Portuguese version EMI2 encompassing fourteen reasons for exercise participation and 49 items was used. The model displayed acceptable fit as seen in Table 3. Internal consistency was above cutoffs ranging from .71 (strength and endurance) to .83 (enjoyment).

\section{Statistical Analysis}

First, univariate of central tendency (mean) and dispersion (standard deviation) measures analysis was conducted. Second, we used t-test for independent samples to assess differences between female $(n=342)$ and male $(n=171)$, and a one-way ANOVA to compare means between age groups and exercise activities. Age groups were created as following: 1) 
Table 5 Measurement invariance between samples and gender

\begin{tabular}{|c|c|c|c|c|c|c|c|c|c|c|c|}
\hline & $x^{2}$ & df & $\Delta \chi^{2}$ & $\Delta \mathrm{df}$ & $\mathrm{B}-\mathrm{S} p$ & CFI & $\Delta \mathrm{CFI}$ & RMSEA & $\triangle \mathrm{RMSEA}$ & SRMR & $\triangle \mathrm{SRMR}$ \\
\hline \multicolumn{12}{|c|}{ Calibration and Validation sample } \\
\hline Configural & 8350.874 & 2070 & - & - & $<.001$ & .907 & - & .052 & - & .054 & - \\
\hline Metric & 8350.914 & 2100 & .04 & 30 & $<.001$ & .906 & .001 & .054 & .002 & .054 & .000 \\
\hline Scalar & 8351.078 & 2210 & .20 & 140 & $<.001$ & .906 & .001 & .054 & .002 & .055 & .001 \\
\hline Residual & 8351.296 & 2260 & .42 & 190 & $<.001$ & .904 & .003 & .056 & .004 & .058 & .004 \\
\hline \multicolumn{12}{|c|}{ Female and Male sample } \\
\hline Configural & 8199.312 & 2070 & - & - & $<.001$ & .904 & - & .055 & - & .055 & - \\
\hline Metric & 8281.198 & 2100 & 81.89 & 30 & $<.001$ & .903 & .001 & .053 & .002 & .058 & .003 \\
\hline Scalar & 8588.247 & 2210 & 388.92 & 140 & $<.001$ & .901 & .003 & .054 & .001 & .063 & .008 \\
\hline Residual & 9048.644 & 2260 & 849.33 & 190 & $<.001$ & .896 & .008 & .065 & .010 & .065 & .010 \\
\hline
\end{tabular}

B-S $p$ Bollen-Stine level of significance, $\triangle C F I$ differences in CFI, $\triangle R M S E A$ differences in RMSEA, $\triangle S R M R$ differences in SRMR

young adults from 18 to 35 years $(n=123) ; 2)$ middle-age adults from 36 to 60 years $(n=240)$, and; 3$)$ elderly from 61 years and beyond $(n=152)$ based on Petry (2002) stereotype classification. Regarding exercise activities, participants were grouped in: i) fitness group classes $(n=145)$, ii) water activities $(n=124)$; or, cardio/resistance training $(n=246)$.

ANOVA was supplemented with the Tukey post-hoc test if the Levene's test revealed homogeneity within sample, as suggested by Ho (2014). The significance level was set at $p \leq .05$ to reject the null hypothesis, and IBM SPSS STATISTICS 23.0 for statistical analysis was used. The $d$ Cohen (1988) was calculated to obtain the correspondent effect size for t-test analysis, considering: trivial (0-.19); small (.2-.49), average (.5-.79) and large (greater than or equal to $.80)$ and $\eta^{2}$ was measured for ANOVA analysis to observe the effect size between groups, considering: small (.1-.06), medium (.06-.14) and large (greater than .14).

\section{Results}

\section{Gender Differences}

There were significant differences between male and female exercisers in nine of fourteen motives: stress management, revitalization, positive health, agility, strength and endurance, social recognition, competition, weight management, and appearance, as seen in Table 6. Thus, $d$ value exhibited small to average effect size in these factors, except for strength and endurance showing trivial effect.

\section{Age and Exercise Activity Differences}

Differences between age groups and exercise activities are displayed in Tables 7 and 8, respectively. The most significant differences were found between young and middle-aged adults in revitalization, enjoyment, health pressure, strength and endurance, and appearance. No differences were found between middle-aged adults and elderly, thus elderly exhibited differences with young adults in the health pressure motive. Partial eta squared show small to medium effect, being health pressure the factor with the highest effect size. Regarding exercise activities, fitness group classes show differences in stress management, challenge, and competition with water activities. Results found differences between water activities and cardio/resistance training in health pressure, ill-health avoidance, strength and endurance, and appearance. Partial eta squared show zero to small effect size between these groups.

\section{Discussion}

In this second study we aimed to compare means across gender, age, and exercise activities, thus, results showed differences among all groups. As explained by Vlachopoulos et al. (2013), distinct characteristics between individuals could lead to different motives for exercise participation. Results corroborate with this statement and will be discussed according to past literature.

Participants in current study listed stress management, revitalization, enjoyment, positive health, and agility as their top motives for engaging in regular exercise. This results are similar to previous research (Egli et al. 2011; Ferrand et al. 2008; Smith et al. 1998), showing that psychological motives (stress management, revitalization, enjoyment), general health (positive health), and agility (physical fitness) are among the top reasons for people to endorse in regular exercise. However, male and female practice for different reasons. In fact, only five of fourteen motives had no significant differences between gender, namely: enjoyment, challenge, health pressure, ill-health avoidance, and affiliation. As stated by Vlachopoulos et al. (2013), women are more often motivated to endorse in exercising due to body image perception or social interaction compared to men. On the other hand, it 
Table 6 Mean differences between gender

\begin{tabular}{|c|c|c|c|c|c|c|c|c|}
\hline & \multirow[t]{2}{*}{$\mathrm{G}$} & \multirow[t]{2}{*}{ M } & \multirow[t]{2}{*}{$\mathrm{SD}$} & \multirow[t]{2}{*}{$\mathrm{t}$} & \multirow[t]{2}{*}{$p$} & \multicolumn{2}{|l|}{$\mathrm{CI} 95 \%$} & \multirow[t]{2}{*}{$d$} \\
\hline & & & & & & Lower & Upper & \\
\hline \multirow[t]{2}{*}{ Stress Management } & $\mathrm{F}$ & 3.91 & .98 & -6.17 & $* *$ & -.79 & -.41 & .59 \\
\hline & M & 3.31 & 1.17 & & & & & \\
\hline \multirow[t]{2}{*}{ Revitalization } & $\mathrm{F}$ & 4.09 & .79 & -3.53 & $* *$ & -.40 & -.11 & .32 \\
\hline & $\mathrm{M}$ & 3.84 & .76 & & & & & \\
\hline \multirow[t]{2}{*}{ Enjoyment } & $\mathrm{F}$ & 3.73 & .96 & -1.58 & .11 & -.32 & .03 & .14 \\
\hline & M & 3.59 & .97 & & & & & \\
\hline \multirow[t]{2}{*}{ Challenge } & $\mathrm{F}$ & 2.33 & 1.17 & 1.44 & .15 & -.06 & .37 & .13 \\
\hline & $\mathrm{M}$ & 2.49 & 1.18 & & & & & \\
\hline \multirow[t]{2}{*}{ Health Pressure } & $\mathrm{F}$ & 1.75 & 1.41 & -0.78 & .44 & -.36 & .15 & .07 \\
\hline & M & 1.65 & 1.35 & & & & & \\
\hline \multirow[t]{2}{*}{ Positive Health } & $\mathrm{F}$ & 4.29 & .76 & -2.72 & $* *$ & -.33 & -.05 & .25 \\
\hline & $\mathrm{M}$ & 4.10 & .74 & & & & & \\
\hline \multirow[t]{2}{*}{ Ill-Health Avoidance } & $\mathrm{F}$ & 3.60 & 1.03 & -1.43 & .15 & -.32 & .05 & .13 \\
\hline & $\mathrm{M}$ & 3.47 & 1.00 & & & & & \\
\hline \multirow[t]{2}{*}{ Agility } & $\mathrm{F}$ & 3.81 & .88 & -2.82 & $* *$ & -.41 & -.07 & .26 \\
\hline & M & 3.57 & .97 & & & & & \\
\hline \multirow[t]{2}{*}{ Strength and Endurance } & $\mathrm{F}$ & 3.37 & .96 & 2.02 & $*$ & .00 & .36 & .18 \\
\hline & M & 3.55 & 1.01 & & & & & \\
\hline \multirow[t]{2}{*}{ Affiliation } & $\mathrm{F}$ & 2.49 & 1.18 & -.50 & .61 & -.28 & .17 & .05 \\
\hline & $\mathrm{M}$ & 2.43 & 1.31 & & & & & \\
\hline \multirow[t]{2}{*}{ Social Recognition } & $\mathrm{F}$ & .91 & 1.03 & 4.92 & $* *$ & .31 & .72 & .43 \\
\hline & M & 1.41 & 1.27 & & & & & \\
\hline \multirow[t]{2}{*}{ Competition } & $\mathrm{F}$ & 1.41 & 1.21 & 6.73 & $* *$ & .58 & 1.05 & .66 \\
\hline & M & 2.23 & 1.44 & & & & & \\
\hline \multirow[t]{2}{*}{ Weight Management } & $\mathrm{F}$ & 3.44 & 1.06 & -.66 & $* *$ & -.79 & -.38 & .52 \\
\hline & M & 2.85 & 1.21 & & & & & \\
\hline \multirow[t]{2}{*}{ Appearance } & $\mathrm{F}$ & 3.15 & 1.16 & -5.27 & $* *$ & -.83 & -.38 & .48 \\
\hline & M & 2.55 & 1.35 & & & & & \\
\hline
\end{tabular}

$G$ Gender, $M$ Mean, $S D$ Standard Deviation, $t$ t-test value, $p$ level of significance, $d$ effect size; * $p \leq .05$;** $p \leq .01 ;$ degrees of freedom $=512$

seems that men prefer exercising for competition, physical fitness, and health equated to women. As results show, male exercisers are more intrinsically oriented for physical activity practice, whereas female do it for extrinsic reasons. Intrinsic motives are related to self-determined motivation, explaining that individuals who act on a certain behavior for the pleasure of doing it so are more likely to experience positive outcomes (Ryan \& Deci, 2017). On the other hand, it seems that individuals who engage in exercise for extrinsic reasons are more endeavor to withdrawal (Sebire et al. 2008). Therefore, understanding why male and female engage in exercise is of upmost importance (Craft et al. 2014).

Results showed that young adults are more interested in pleasure, strength and endurance, and appearance compared to middle-aged adults. These results contradict past findings (Brunet and Sabiston 2011; Molanorouzi et al. 2015) showing that young individuals interest in others perception of selfimage, enjoy exercising, and want to improve physical fitness. Looking at middle-aged adult aspirations for exercising, health pressure and revitalization represented the top reasons.
The increase of non-communicable disease related to aging, physical inactivity, sedentary behaviors, as well as professional pressure could explain present findings (Brooks and Ferro 2012; Din et al. 2015). Last, elderly rank highly general health, enjoyment, and revitalization supporting past literature (Gutierrez et al. 2018; Kolt et al. 2004) investigating the reasons in older adults for regular exercise. Thus, it is rational to expect present results would show more concern for physical and psychological health, since it impacts more their decisions to engage in exercise over time. Current results suggest changes in motives during life-span, based on several studies (Buhler 1967; Ingledew et al. 1998).

Looking at exercise activities, fitness group classes and water activities show differences in stress management, challenge, and competition. Water activities reported higher means and could be explained by the activities performed in the swimming pool. We encompassed recreational activities such as water gymnastic with swimming lessons. Exercisers with swimming lessons may have recreational competitions as a way of testing their skills. Clancy et al. (2017) have shown 
Table 7 One-way ANOVA results across age groups

\begin{tabular}{|c|c|c|c|c|c|c|c|c|c|c|}
\hline & \multirow[t]{2}{*}{ G } & \multirow[t]{2}{*}{$\mathrm{M}$} & \multirow[t]{2}{*}{$\mathrm{SD}$} & \multirow[t]{2}{*}{$\mathrm{L}$} & \multirow[t]{2}{*}{$\mathrm{F}^{\#}$} & \multirow[t]{2}{*}{ Differences } & \multirow[t]{2}{*}{$p$} & \multicolumn{2}{|l|}{$\mathrm{CI} 95 \%$} & \multirow[t]{2}{*}{$\eta^{2}$} \\
\hline & & & & & & & & Lower & Upper & \\
\hline \multirow[t]{3}{*}{ Stress Management } & YA & 3.75 & 1.06 & \multirow[t]{3}{*}{1.37} & \multirow[t]{3}{*}{1.13} & $\mathrm{YA}-\mathrm{MA}$ & .27 & -.09 & .42 & \multirow[t]{3}{*}{.01} \\
\hline & MA & 3.59 & 1.15 & & & YA - EL & .99 & -.69 & .65 & \\
\hline & EL & 3.78 & .93 & & & MA - EL & .79 & -.88 & .50 & \\
\hline \multirow[t]{3}{*}{ Revitalization } & YA & 4.09 & .70 & \multirow[t]{3}{*}{$10.16^{* *}$} & \multirow[t]{3}{*}{6.92} & $\mathrm{YA}-\mathrm{MA}$ & $* *$ & .10 & .47 & \multirow[t]{3}{*}{.03} \\
\hline & MA & 3.81 & .99 & & & YA - EL & .65 & -30 & .67 & \\
\hline & EL & 3.91 & .71 & & & MA - EL & 88 & -.61 & .40 & \\
\hline \multirow[t]{3}{*}{ Enjoyment } & YA & 3.83 & .87 & \multirow[t]{3}{*}{$7.06^{* *}$} & \multirow[t]{3}{*}{14.99} & YA - MA & $* *$ & .28 & .72 & \multirow[t]{3}{*}{.06} \\
\hline & MA & 3.34 & 1.09 & & & YA - EL & .13 & -.10 & 1.07 & \\
\hline & EL & 3.35 & 1.10 & & & MA - EL & .99 & -.62 & .59 & \\
\hline \multirow[t]{3}{*}{ Challenge } & YA & 2.48 & 1.16 & .03 & 3.89 & YA - MA & 03 & .02 & .56 & .02 \\
\hline & MA & 2.19 & 1.17 & & & YA - EL & .32 & -28 & 1.17 & \\
\hline & EL & 2.03 & 1.21 & & & MA - EL & .88 & -.59 & .90 & \\
\hline Health Pressure & YA & 1.45 & 1.27 & $3.12^{*}$ & 24.50 & $\mathrm{YA}-\mathrm{MA}$ & $* *$ & -1.13 & -.51 & .09 \\
\hline & MA & 2.27 & 1.44 & & & YA - EL & $* *$ & -2.20 & -.55 & \\
\hline & EL & 2.82 & 1.68 & & & MA - EL & .28 & -1.40 & .30 & \\
\hline Positive Health & YA & 4.28 & .71 & $3.39 *$ & 2.75 & $\mathrm{YA}-\mathrm{MA}$ & .07 & -.01 & .34 & .01 \\
\hline & MA & 4.12 & .86 & & & YA - EL & .53 & -.25 & .68 & \\
\hline & EL & 4.07 & .74 & & & MA - EL & .97 & -.43 & .53 & \\
\hline Ill-Health & YA & 3.44 & 1.04 & 2.17 & 8.78 & $\mathrm{YA}-\mathrm{MA}$ & $* *$ & -.59 & -.12 & .03 \\
\hline Avoidance & MA & 3.80 & .93 & & & YA - EL & .03 & -1.29 & -.04 & \\
\hline & EL & 4.11 & .69 & & & MA - EL & .50 & -.95 & .33 & \\
\hline Agility & YA & 3.78 & .86 & 1.91 & 2.09 & $\mathrm{YA}-\mathrm{MA}$ & .20 & -.06 & .37 & .01 \\
\hline & MA & 3.62 & 1.03 & & & $\mathrm{YA}-\mathrm{EL}$ & .40 & -.26 & .88 & \\
\hline & EL & 3.47 & 1.03 & & & MA - EL & .81 & -.43 & .74 & \\
\hline Strength and & YA & 3.54 & .91 & 2.68 & 7.91 & YA - MA & $* *$ & .16 & .61 & .03 \\
\hline Endurance & MA & 3.15 & 1.09 & & & YA - EL & .89 & -.48 & .72 & \\
\hline & EL & 3.42 & 1.10 & & & MA - EL & .58 & -.88 & .35 & \\
\hline Affiliation & YA & 2.54 & 1.19 & 2.21 & 2.43 & $\mathrm{YA}-\mathrm{MA}$ & .21 & -.08 & .49 & .01 \\
\hline & MA & 2.34 & 1.27 & & & YA - EL & .26 & -.25 & 1.27 & \\
\hline & EL & 2.03 & 1.59 & & & MA - EL & .64 & -.48 & 1.08 & \\
\hline Social & YA & 1.03 & 1.08 & $5.00 * *$ & 1.49 & $\mathrm{YA}-\mathrm{MA}$ & .45 & -.40 & .13 & .01 \\
\hline Recognition & MA & 1.16 & 1.27 & & & YA - EL & .36 & -1.12 & .30 & \\
\hline & EL & 1.43 & 1.32 & & & MA - EL & .65 & -1.00 & .46 & \\
\hline Competition & YA & 1.71 & 1.34 & .009 & .21 & $\mathrm{YA}-\mathrm{MA}$ & .83 & -.24 & .39 & .00 \\
\hline & MA & 1.63 & 1.37 & & & YA - EL & .93 & -.71 & .96 & \\
\hline & EL & 1.58 & 1.38 & & & MA - EL & .99 & -.81 & .91 & \\
\hline Weight & YA & 3.33 & 1.13 & .056 & 3.12 & $\mathrm{YA}-\mathrm{MA}$ & .06 & -.01 & .53 & .01 \\
\hline Management & MA & 3.07 & 1.15 & & & YA - EL & .45 & -.35 & 1.07 & \\
\hline & EL & 2.97 & 1.19 & & & MA - EL & .95 & -.63 & .83 & \\
\hline Appearance & YA & 3.11 & 1.17 & $6.37 * *$ & 10.56 & $\mathrm{YA}-\mathrm{MA}$ & $* *$ & .23 & .81 & .04 \\
\hline & MA & 2.60 & 1.39 & & & $\mathrm{YA}-\mathrm{EL}$ & .05 & -.01 & 1.52 & \\
\hline & EL & 2.36 & 1.45 & & & MA - EL & .76 & -.55 & 1.03 & \\
\hline
\end{tabular}

$G$ Gender, $M$ Mean, $S D$ Standard Deviation, $L$ Levene test, $F$ F value, $p$ level of significance, $\eta^{2}$ partial eta squared, $Y A$ Young Adults, $M A$ Middle-aged Adults, $E L$ Elderly; * $p \leq .05 ; * * p \leq .01$; \# = degrees of freedom $(2,512)$

that people who play sports have a tendency to focus on challenging motives. Hence, forthcoming studies should separate water activities and compare samples among activities.

Cardio/resistance training showed differences in health pressure, ill-health avoidance and appearance compared to water activities. Health status and body image seems to be more important for exercisers who like lifting weights compared to those swimming or doing water gymnastics. Considering researchers professional view with current fitness trends, most of modern gym clients search for aesthetics at the cardio/weightlifting room. In fact, when talking about body image/aesthetics, it is predominantly associated with strength training and cardio and not with water activities. Several studies (Rica et al. 2018; SantaBarbara et al. 2017; Seguin et al. 2013) corroborate with this statement explaining that individuals who lift weights or do cardio search and have a better body image satisfaction. Differences found in health pressure and ill-health avoidance motives are surprising, since both types of exercise have shown similar results, for example in knee osteoarthritis treatment (Dong et al. 2018) or in chronic low back pain easement (Sugano and Nomura 2000). One hypothesis may rely on health professionals exercise 
Table 8 One-way ANOVA results across exercise activities

\begin{tabular}{|c|c|c|c|c|c|c|c|c|c|c|}
\hline & \multirow[t]{2}{*}{ G } & \multirow[t]{2}{*}{ M } & \multirow[t]{2}{*}{ SD } & \multirow[t]{2}{*}{$\mathrm{L}$} & \multirow[t]{2}{*}{$\mathrm{F}^{\#}$} & \multirow[t]{2}{*}{ Differences } & \multirow[t]{2}{*}{$P$} & \multicolumn{2}{|l|}{ CI95\% } & \multirow[t]{2}{*}{$\eta^{2}$} \\
\hline & & & & & & & & Lower & Upper & \\
\hline \multirow[t]{3}{*}{ Stress Management } & $\mathrm{FG}$ & 3.87 & .94 & \multirow[t]{3}{*}{1.79} & \multirow[t]{3}{*}{2.94} & $\mathrm{FG}-\mathrm{WA}$ & .04 & .01 & .54 & \multirow[t]{3}{*}{.01} \\
\hline & WA & 3.60 & 1.15 & & & $\mathrm{FG}-\mathrm{CR}$ & .60 & -.18 & .44 & \\
\hline & CR & 3.74 & 1.07 & & & $\mathrm{WA}-\mathrm{CR}$ & .45 & -.42 & .14 & \\
\hline \multirow[t]{3}{*}{ Revitalization } & $\mathrm{FG}$ & 4.09 & .74 & \multirow[t]{3}{*}{1.85} & \multirow[t]{3}{*}{1.35} & FG - WA & .64 & -.12 & .27 & \multirow[t]{3}{*}{.01} \\
\hline & WA & 4.01 & .79 & & & $\mathrm{FG}-\mathrm{CR}$ & .23 & -.07 & .39 & \\
\hline & $\mathrm{CR}$ & 3.93 & .86 & & & $\mathrm{WA}-\mathrm{CR}$ & .60 & -.12 & .29 & \\
\hline \multirow[t]{3}{*}{ Enjoyment } & $\mathrm{FG}$ & 3.70 & .93 & \multirow[t]{3}{*}{.31} & \multirow[t]{3}{*}{1.02} & $\mathrm{FG}-\mathrm{WA}$ & .96 & -.27 & .21 & \multirow[t]{3}{*}{.00} \\
\hline & WA & 3.73 & .96 & & & $\mathrm{FG}-\mathrm{CR}$ & .56 & -.16 & .40 & \\
\hline & CR & 3.58 & 1.03 & & & $\mathrm{WA}-\mathrm{CR}$ & .34 & -.10 & .40 & \\
\hline \multirow[t]{3}{*}{ Challenge } & $\mathrm{FG}$ & 2.19 & 1.13 & 1.49 & 4.87 & $\mathrm{FG}-\mathrm{WA}$ & .01 & -.65 & -.08 & .02 \\
\hline & WA & 2.55 & 1.22 & & & $\mathrm{FG}-\mathrm{CR}$ & .71 & -.45 & .22 & \\
\hline & CR & 2.30 & 1.09 & & & WA - CR & .12 & -.05 & .55 & \\
\hline Health Pressure & $\mathrm{FG}$ & 1.73 & 1.47 & $3.78 *$ & 5.00 & $\mathrm{FG}-\mathrm{WA}$ & .43 & -.16 & .52 & .02 \\
\hline & WA & 1.55 & 1.29 & & & $\mathrm{FG}-\mathrm{CR}$ & .18 & -.70 & .10 & \\
\hline & $\mathrm{CR}$ & 2.03 & 1.45 & & & $\mathrm{WA}-\mathrm{CR}$ & $* *$ & -.84 & -12 & \\
\hline Positive Health & $\mathrm{FG}$ & 4.27 & .76 & 1.91 & .26 & $\mathrm{FG}-\mathrm{WA}$ & .86 & -.14 & .23 & .00 \\
\hline & WA & 4.22 & .79 & & & $\mathrm{FG}-\mathrm{CR}$ & .77 & -.15 & .28 & \\
\hline & CR & 4.20 & .69 & & & $\mathrm{WA}-\mathrm{CR}$ & .96 & -.17 & .22 & \\
\hline Ill-Health & $\mathrm{FG}$ & 3.55 & 1.02 & $6.73 * *$ & 3.78 & $\mathrm{FG}-\mathrm{WA}$ & .72 & -.17 & .33 & .02 \\
\hline Avoidance & WA & 3.47 & 1.09 & & & $\mathrm{FG}-\mathrm{CR}$ & .17 & -.51 & .07 & \\
\hline & $\mathrm{CR}$ & 3.77 & .82 & & & WA - CR & .02 & -.57 & -04 & \\
\hline Agility & $\mathrm{FG}$ & 3.77 & .94 & .10 & .29 & $\mathrm{FG}-\mathrm{WA}$ & .82 & -.17 & .28 & .00 \\
\hline & WA & 3.72 & .93 & & & $\mathrm{FG}-\mathrm{CR}$ & .74 & -.18 & .35 & \\
\hline & CR & 3.69 & .85 & & & $\mathrm{WA}-\mathrm{CR}$ & .97 & -.21 & .26 & \\
\hline Strength and & $\mathrm{FG}$ & 3.32 & 1.06 & .76 & 3.82 & $\mathrm{FG}-\mathrm{WA}$ & .06 & -.47 & .01 & .02 \\
\hline Endurance & WA & 3.55 & .96 & & & $\mathrm{FG}-\mathrm{CR}$ & .97 & -.27 & .29 & \\
\hline & $\mathrm{CR}$ & 3.31 & .89 & & & WA - CR & .06 & -.01 & .49 & \\
\hline Affiliation & $\mathrm{FG}$ & 2.65 & 1.16 & 1.72 & 3.12 & $\mathrm{FG}-\mathrm{WA}$ & .32 & -.12 & .49 & .01 \\
\hline & WA & 2.46 & 1.24 & & & $\mathrm{FG}-\mathrm{CR}$ & .03 & .02 & .72 & \\
\hline & $\mathrm{CR}$ & 2.28 & 1.25 & & & $\mathrm{WA}-\mathrm{CR}$ & .34 & -.13 & .50 & \\
\hline Social & FG & .98 & 1.11 & 1.25 & .76 & FG - WA & .44 & -.43 & .13 & .00 \\
\hline Recognition & WA & 1.12 & 1.18 & & & $\mathrm{FG}-\mathrm{CR}$ & .71 & -.44 & .22 & \\
\hline & CR & 1.09 & 1.10 & & & $\mathrm{WA}-\mathrm{CR}$ & .95 & -.26 & .33 & \\
\hline Competition & $\mathrm{FG}$ & 1.49 & 1.26 & $4.23 *$ & 2.78 & $\mathrm{FG}-\mathrm{WA}$ & .05 & -.66 & .00 & .01 \\
\hline & WA & 1.82 & 1.43 & & & $\mathrm{FG}-\mathrm{CR}$ & .62 & -.54 & .23 & \\
\hline & $\mathrm{CR}$ & 1.65 & 1.26 & & & WA - CR & .47 & -.17 & .52 & \\
\hline Weight & $\mathrm{FG}$ & 3.32 & 1.15 & .02 & 1.845 & $\mathrm{FG}-\mathrm{WA}$ & .97 & -.25 & .31 & .01 \\
\hline Management & WA & 3.29 & 1.15 & & & $\mathrm{FG}-\mathrm{CR}$ & .19 & -.09 & .57 & \\
\hline & $\mathrm{CR}$ & 3.08 & 1.13 & & & WA - CR & .21 & -.08 & .51 & \\
\hline Appearance & $\mathrm{FG}$ & 2.90 & 1.27 & 1.54 & 6.58 & $\mathrm{FG}-\mathrm{WA}$ & .19 & -.54 & .08 & .03 \\
\hline & WA & 2.64 & 1.28 & & & $\mathrm{FG}-\mathrm{CR}$ & .20 & -.09 & .62 & \\
\hline & CR & 3.13 & 1.22 & & & $\mathrm{WA}-\mathrm{CR}$ & $* *$ & .17 & .82 & \\
\hline
\end{tabular}

$G$ Groups, $M$ Mean, $S D$ Standard Deviation, $L$ Levene test, $F$ F value, $p$ level of significance, $\eta^{2}$ partial eta squared, $F G$ Fitness Group classes, $W A$ Water Activities, $C R$ Cardio/Resistance training; * $p \leq .05 ; * * p \leq .01$; $\#=$ degrees of freedom $(2,512)$

recommendations. Given the fact that not all gym and fitness centers are equipped with swimming pools, and since walking/running is economically cheaper, health and exercise professionals may suggest individuals to do cardio at the treadmill or outdoor. However, this statement is purely speculative and forthcoming studies should analyze in more detail differences between exercise activities.

Current findings suggest that people endorsing in fitness group classes search for affiliation and acceptance compared to those working out in the cardio/resistance machine room. In an empirical view, a sense of belonging is expressive in those individuals who do high intensity group classes, and in present study this group was composed predominantly of women (80\%). As stated by Markland and Ingledew (1997), women are more likely to seek social aspirations compared to men and this could have influenced present results. On the other hand, it seems that people bench pressing or squatting do not experience the need to feel affiliate or integrated in a group. Nevertheless, as expressed by Ryan and Deci (2017) relatedness (i.e., sense of belonging, connection with other people) is important as it forecast intrinsic motivation, leading to positive outcomes such as physical exercise commitment and 
well-being. Therefore, it is essential human interaction and supporting interpersonal behaviors by peers and fitness professionals so that no one should perceive "loneliness" when exercising (Rocchi and Pelletier 2018).

\section{General Discussion}

In overall, the EMI-2 seems to be a reliable instrument assessing exercise motives in Portuguese individuals. However, different people have different motives and exercise professionals should support individual reasons for exercising and not impose one's ideals on others. Exercise professionals should be attentive to this situation when questioning individuals for their motives. If they perceive that the gym client is exercising for extrinsic motives (e.g., for social recognition), it could be of importance to guide them from extrinsic to intrinsic reasons, keeping always in mind that they can exercise for both types, and that this could be positive in some moments. Fitness group instructors and personal trainers need to be aware of differences between individuals (gender, age, exercise activity) when encouraging exercise within population. For example, in group class activities (e.g., indoor cycling, aerobics, step) exercise professionals might pay attention to different aspects of gym clients characteristics, because studies have enlightened that physical activity levels decline more in female than male when both participated together in mixedgender classes (Molanorouzi et al. 2014, 2015).

\section{Limitations and Future Agenda}

Present research has some limitations that should be addressed. First, this study had a cross-sectional design and longitudinal/experimental studies can be helpful in measuring temporal/longitudinal invariance. Nonetheless, our analysis supports the original fourteen motive instrument, exhibiting a good reliability in Portuguese exercisers. We agree in an empirical manner with Markland and Hardy (1993) that motives for exercise participation could change over time. A person who engages in physical for the first time could be endorsed mainly for health motives but after exercising regularly, some other reasons could arise such as stress management or enjoyment. Thus, future studies should make an effort and analyze the reasons for the practice of exercise over time.

Second, forthcoming studies are needed to test possible multidimensionality. Although the present second-order model falls short on achieving fit, reviewing this scale using advanced methodological approaches such as Exploratory Structural Equation Modelling (Muthén and Muthén 2010) could explain factor dimensionality. More multi-group analysis, namely latent mean differences procedures, are recommended to measure how exercise motives are perceived by different groups.
Last, future research should examine in detail how each motive predicts self-determined motivation, according to Self-Determination Theory (Ryan and Deci 2017) in exercise context. We speculate that self-endorsed focused motives (focus on how the person feels about himself) could predict more autonomous forms of motivation, contrarily to other-endorsed focused motives (focus on how others perceive me or how I could be accepted by others) possibly will forecast more controlled forms of motivation. Although this assertion is speculative, some research (Ingledew and Markland 2008; Ingledew et al. 2014) does support our hypothesis.

\section{Conclusion}

The uniqueness of this study is to emphasize the proper use of a valid and invariant instrument for measuring exercise motives participation. Overall, present findings support factorial and construct validity of the original first-order EMI-2, providing new literature for construct distinctiveness of fourteen exercise motives. In addition, the model was invariant across calibration and validation sample and gender presenting a measurement equivalence. Exercise participation depends on individual characteristics, where men are more focused on intrinsic reasons (e.g., health, revitalization, physical fitness) and women more on extrinsic reasons (e.g., social recognition, body image). In addition, current study showed that age and gym activities influence exercise motives. This was the first research testing mean differences between age groups and exercise activities, thus more studies are needed to assess differences in other characteristics (e.g., economic status, lowcost vs premium fitness center). Scale analysis is a constant process; hence, future studies will increase our understanding on exercise motives assessment.

Funding Information This work was supported by the National Funding through the Portuguese Foundation for Science and Technology, I.P., under the project UID/DTP/04045/2019.

\section{Conflict of Interest None.}

Approval Approval from the Ethical Committee (CE-UBI-pJ-2018044:ID683) was obtained.

\section{References}

Alves, J., \& Lourenço, A. (2003). Tradução e adaptação do Questionário de Motivação para o Exercício (Exercise Motivation Inventory 2 EMI2). Desporto, Investigação \& Ciência, 2, 3-11.

Baptista, P., Monteiro, D., Alves, S., Cid, L., \& Moutão, J. (2014). Desenvolvimento e validação de uma versão reduzida do Exercise Motivation Inventory-2p. Revista da UIIPS, 2(2), 175-189 http:// hdl.handle.net/10400.15/1913. 
Brooks, J., \& Ferro, A. (2012). The physician's role in prescribing physical activity for the prevention and treatment of essential hypertension. JRSM Cardiovascular Disease, 1(4). https://doi.org/10.1258/ cvd.2012.012012.

Brunet, J., \& Sabiston, C. (2011). Exploring motivation for physical activity across the adult lifespan. Psychology of Sport and Exercise, 12(2), 99-105. https://doi.org/10.1016/j.psychsport.2010.09.006.

Buhler, C. (1967). Human life goals in the humanistic perspective. Journal of Humanistic Psychology, 1, 36-52. https://doi.org/10. 1177/002216786700700105.

Byrne, B. (2016). Structural equation modeling with AMOS. Basic concepts, applications, and programming (3rd ed.). New York: Taylor \& Francis Group, LLC.

Cham, H., Reshetnyak, E., Rosenfeld, B., \& Breitbart, W. (2017). Full information maximum likelihood estimation for latent variable interactions with incomplete indicators. Multivariate Behavioral Research, 52(1), 12-30. https://doi.org/10.1080/00273171.2016. 1245600.

Chen, F. (2007). Sensitivity of goodness of fit indexes to lack of measurement invariance. Structural Equation Modeling: A Multidisciplinary Journal, 14(3), 464-504. https://doi.org/10.1080/ 10705510701301834.

Chen, F. (2008). What happens if we compare chopsticks with forks? The impact of making inappropriate comparisons in cross-cultural research. Journal of Personality \& Social Psycholgy, 95(5), 10051018. https://doi.org/10.1037/a0013193.

Cheung, G., \& Rensvold, R. (2002). Evaluating goodness-of-fit indexes for testing measurement invariance. Structural Equation Modeling: A Multidisciplinary Journal, 9(2), 233-255. https://doi.org/10.1207/ s15328007sem0902 5 .

Cid, L., Silva, C., \& Alves, J. (2007). Actividade física e bem-estar psicológico - perfi 1 dos participantes no programa de exercício e saúde de rio maior. Motricidade, 3(2), 47-55.

Clancy, R., Herring, M., \& Campbell, M. (2017). Motivation measures in sport: A critical review and bibliometric analysis. Frontiers in Psychology, 8, 348. https://doi.org/10.3389/fpsyg.2017.00348.

Cohen, J. (1988). A power primer. Psychological Bulletin, 112(1), 155159. https://doi.org/10.1037/0033-2909.112.1.155

Craft, B., Carroll, H., \& Lustyk, M. (2014). Gender differences in exercise habits and quality of life reports: Assessing the moderating effect of reasons for exercise. International Journal of Libreral Art \& Social Science, 2(5), 65-76.

Dacey, M., Baltzell, A., \& Zaichkowsky, L. (2008). Older adults' intrinsic and extrinsic motivation toward physical activity. American Journal of Health Behavior, 32(6), 570-582. https://doi.org/10.5555/ajhb. 2008.32.6.570.

Din, N., Moore, G., Murphy, S., Wilkinson, C., \& Williams, N. (2015). Health professionals' perspectives on exercise referral and physical activity promotion in primary care: Findings from a process evaluation of the National Exercise Referral Scheme in Wales. Health Education Journal, 74(6), 743-757. https://doi.org/10.1177/ 0017896914559785.

DiStefano, C., \& Hess, B. (2016). Using confirmatory factor analysis for construct validation: An empirical review. Journal of Psychoeducational Assessment, 23(3), 225-241. https://doi.org/10. 1177/073428290502300303.

Dong, R., Wu, Y., Xu, S., Zhang, L., Ying, J., Jin, H., Wang, P., Tong, X. L., \& P. (2018). Is aquatic exercise more effective than land-based exercise for knee osteoarthritis? Medicine (Baltimore), 97(52), e13823. https://doi.org/10.1097/MD.0000000000013823.

Duda, J., \& Tappe, M. (1988). Predictors of personal investment in physical activity amon middle-aged and older adults. Perceptual \& Motor Skills, 66(2), 543-549. https://doi.org/10.2466/pms.1998. 66.2.543.

Egli, T., Bland, H., Melton, B., \& Czech, D. (2011). Influence of age, sex, and race on college students' exercise motivation of physical activity. Journal of American College Health, 59(5), 399-406. https://doi.org/10.1080/07448481.2010.513074.

Ferrand, C., Perrin, C., \& Nasarre, S. (2008). Motives for regular physical activity in women and men: A qualitative study in French adults with type 2 diabetes, belonging to a patients' association. Health \& Social Care in the Community, 16(5), 511-520. https://doi.org/10. 1111/j.1365-2524.2008.00773.x.

Frederick, C., \& Ryan, R. (1993). Differences in motivation for sport and exercise and their relations with participation and mental health. Journal of Sport Behavior, 16(3), 124-146.

Gutierrez, M., Calatayud, P., \& Tomas, J. (2018). Motives to practice exercise in old age and successful aging: A latent class analysis. Archives of Gerontology and Geriatrics, 77, 44-50. https://doi.org/ 10.1016/j.archger.2018.04.003.

Hair, J., Black, W., Babin, B., \& Anderson, R. (2014). Multivariate Data Analysis (7th ed.). New Jersey: Pearson Educational, Inc.

Ho, R. (2014). Handbook of univariate and multivariate data analysis with IBM SPSS (2nd ed.). New York: CRC Press.

Ingledew, D., \& Markland, D. (2008). The role of motives in exercise participation. Psychology \& Health, 23(7), 807-828. https://doi.org/ 10.1080/08870440701405704.

Ingledew, D., Markland, D., \& Medley, A. (1998). Exercise motives and stages of change. Journal of Health Psychology, 3(4), 477-489. https://doi.org/10.1177/135910539800300403.

Ingledew, D., Markland, D., \& Strömmer, S. (2014). Elucidating the roles of motives and gains in exercise participation. Sport Exercise and Performance Psychology, 3(2), 116-131. https://doi.org/10.1037/ spy0000004.

Kenny, D., \& McCoach, D. (2003). Effect of the number of variables on measures of fit in structural euqation modeling. Structural Equation Modeling: A Multidisciplinary Journal, 10, 333-351. https://doi. org/10.1207/S15328007SEM1003_1.

Klain, I., De Matos, D., Cid, L., Aidar, F., Leitão, J., \& Moutão, J. (2015). Evidências de validade da versão brasileira do Exercise Motivation Inventory-2 em contexto de academia e personal training. Motricidade, 11(2), 62-74. https://doi.org/10.6063/motricidade. 3551.

Kolt, G., Driver, R., \& Giles, L. (2004). Why older Australians participate in exercise and sport. Journal of Aging and Physical Activity, 12(2), 185-198. https://doi.org/10.1123/japa.12.2.185.

Markland, D., \& Hardy, L. (1993). The exercise motivations inventory: Preliminary development and validity of a measure of individuals' reasons for participation in regular physical exercise. Personality \& Individual Differences, 15(3), 286-296. https://doi.org/10.1016/ 0191-8869(93)90219-S

Markland, D., \& Ingledew, D. (1997). The measurement of exercise motives: Factorial validity and invariance across gender of a revised exercise motivations inventory. British Journal of Health Psychology, 2(4), 361-376. https://doi.org/10.1111/j.2044-8287. tb00549.x.

Markland, D., \& Ingledew, D. (2007). Exercise participation motives: A self-determination theory perspective. In M. Hagger \& N. Chatzisarantis (Eds.), Intrinsic motivation and self-determination in exercise and sport (pp. 302-305). Champaign: Human Kinetics.

Marsh, H., Hau, K., \& Wen, Z. (2004). In search of Golden rules: Comment on hypothesis-testing approaches to setting cutoff values for fit indexes and dangers in overgeneralizing $\mathrm{Hu}$ and Bentler's (1999) findings. Structural Equation Modeling: A Multidisciplinary Journal, 11(3), 320-341. https://doi.org/10.1207/ s15328007sem1103_2.

Meredith, W. (1993). Measurement invariance, factor analysis and factorial invariance. Psychometrika, 58(4), 525-543. Doi: 1007/BF02294825.

Molanorouzi, K., Khoo, S., \& Morris, T. (2014). Validating the physical Acitivty and leisure motivation scale. BMC Public Health, 14(909), 1-12. https://doi.org/10.1186/1471-2458-14-909. 
Molanorouzi, K., Khoo, S., \& Morris, T. (2015). Motives for adult participation in physical activity: Type of activity, age, and gender. BMC Public Health, 15, 66. https://doi.org/10.1186/s12889-015$1429-7$.

Muthén, L., \& Muthén, B. (2010). Mplus User's Guide. Los Angeles: Muthén \& Muthén.

Nevitt, J., \& Hancock, G. (2001). Performance of bootstrapping approaches to model test statistics and parameter standard error estimation in structural equation modeling. Structural Equation Modeling: A Multidisciplinary Journal, 8(3), 353-377. https://doi. org/10.1207/s15328007sem0803 2.

Ortís, L., Maymí, J., Feliu, J., Vidal, J., Romero, E., Bassets, M., ... Brosa, J. (2007). Exercise motivation in university community members: A behavioural intervention. Psicothema, 19(2), 250-255.

Petry, B. (2002). A comparison of young, middle-aged, and older adult treatment-seeking pathological gamblers. The Gerontologist, 42(1), 92-99.

Podsakoff, P. M., MacKenzie, S. B., Lee, J. Y., \& Podsakoff, N. P. (2003). Common method biases in behavioral research: A critical review of the literature and recommended remedies. Journal of Applied Psychology, 88(5), 879-903. https://doi.org/10.1037/0021-9010. 88.5.879.

Raykov, T. (1997). Estimation of composite reliability for congeneric measures. Applied Psychological Measurement, 21(2), 173-184. https://doi.org/10.1177/01466216970212006.

Rica, R., Gama, E., Machado, A., Alonso, A., Evangelista, A., FigueiraJunior, A., Zanetti, M., Brandão, R., Miranda, M. L. J., Alves, J. V., Bergamin, M., \& Bocalini, D. (2018). Does resistance training improve body image satisfaction among the elderly? A cross-sectional study. Clinics (São Paulo, Brazil), 73, e290. https://doi.org/10.6061/ clinics/2018/e290.

Roberts, S., Reeves, M., \& Ryrie, A. (2014). The influence of physical activity, sport and exercise motives among UK-based university students. Journal of Further and Higher Education, 39(4), 598607. https://doi.org/10.1080/0309877x.2014.938265.

Rocchi, M., \& Pelletier, L. (2018). How does coaches' reported interpersonal behavior align with athletes' perceptions? Consequences for female athletes' psychological needs in sport. Sport, Exercise, \& Performance Psychology, 7(2), 141-154. https://doi.org/10.1037/ spy0000116.

Ryan, R., \& Deci, E. (2017). Self-determination theory. Basic Psychological Needs in Motivation, Development, and Wellness: New York: Guildford Press.
Ryan, R., Frederick, C., Lepes, D., Rubio, N., \& Sheldon, K. (1997). Intrinsic motivation and exercise adherence. International Journal of Sport Psychology, 28(4), 335-354.

SantaBarbara, N., Whitworth, J., \& Ciccolo, J. (2017). A systematic review of the effects of resistance training on body image. Journal of Strength \& Conditioning Research, 31(10), 2880-2888. https://doi. org/10.1519/JSC.0000000000002135.

Sass, D. (2011). Testing measurement invariance and comparing latent factor means within a confirmatory factor analysis framework. Journal of Psychoeducational Assessment, 29(4), 347-363. https:// doi.org/10.1177/0734282911406661.

Schmitt, T. A. (2011). Current methodological considerations in exploratory and confirmatory factor analysis. Journal of Psychoeducational Assessment, 29(4), 304-321. https://doi.org/10. 1177/0734282911406653.

Sebire, S., Standage, M., \& Vansteenkiste, M. (2008). Development and validation of the goal content for exercise questionnaire. Journal of Sport \& Exercise Psychology, 30(4), 353-377. https://doi.org/10. 1123/jsep.30.4.353.

Seguin, R., Eldridge, G., Lynch, W., \& Paul, L. (2013). Strength training improves body image and physical activity behaviors among midlife and older rural women. Journal of Extension, 51(4), 4FEA2.

Smith, B., Handley, P., \& Eldredge, D. (1998). Sex differences in exercise motivation and body-image satisfaction among college students. Perceptual \& Motor Skills, 86(2), 723-732. https://doi.org/10. 2466/pms.1998.86.2.723.

Sugano, A., \& Nomura, T. (2000). Influence of water exercise and land stretching on salivary cortisol concentrations and anxiety in chronic low back pain patients. Journal of Physiological Anthropology and Applied Human Science, 19(4), 175-180.

Vlachopoulos, S., Asci, F., Cid, L., Ersoz, G., González-Cutre, D., Moreno-Murcia, J., \& Moutão, J. (2013). Cross-cultural invariance of the basic psychological needs in exercise scale and need satisfaction latent mean differences among Greek, Spanish, Portuguese and Turkish samples. Psychology of Sport and Exercise, 14(5), 622-631. https://doi.org/10.1016/j.psychsport.2013.03.002.

Publisher's Note Springer Nature remains neutral with regard to jurisdictional claims in published maps and institutional affiliations. 